\title{
Analysis on the Relationship between School Belonging and Learning Burnout of University Students
}

\author{
Hong-yu Xie ${ }^{1, \text { a }}$, He Xiao ${ }^{2, ~ b}$ \\ ${ }^{1}$ Evaluation Division, Neijiang Normal University, Neijiang, Sichuan \\ ${ }^{2}$ College of Foreign Language, Neijiang Normal University, Neijiang, Sichuan \\ 1530100981@qq.com \\ 350080562@qq.com
}

\begin{abstract}
In order to explore the relationship between school belonging and learning burnout of university students, the school belonging scale and the learning burnout scale were used to test 150 college students from different university of Sichuan Province in this paper. The results showed the following: (1) there were some factors which not only affect the school belonging of university students, but also have the direct relationship with learning burnout, like sex, types of subjects, origin, and grades. (2) The lower the sense of school belonging, the worse the learning burnout. However, the sense of learning burnout still exist not matter the higher or lower school belonging or not. This paper is mainly to improve the learning sense of university students and promote healthy body and sound mind among university students through study.
\end{abstract}

Keywords-College Students; School Belonging; Learning Burnout; Sichuan Province

\section{INTRODUCTION}

The sense of school belonging is the needs of belonging and love in Maslow's hierarchy of needs. Janis (2003) defines school belonging as the sense of school communication. It means that students are aware of the positive support and concern of others in school.

Chinese scholar Bao Kebing, Xu Qinmei (2006) believe that the school belonging is a sense of recognition and input in thought, emotional and psychological aspects, like students are willing to participate in school activities, and are willing to responsible for the works in school. And the school belonging is defined as the safety of students, respect for school, and teacher support and peer relationships and so on [1-2].

Recently, more and more scholars are paying attention to the study of school belonging or analysis of the learning burnout of university students, but there is little research on the relationship between school belonging and learning burnout. So this paper is mainly to study whether there exist a relationship between the school belonging and learning burnout, [3] so that to improve the learning senses of university students and cultivate good interpersonal quality, and promote the healthy of body and mind among university students.

\section{RESEARCH METHODS}

\section{A. Study subject}

The cluster sampling method was used in this paper, and 150 students were selected from different universities in Sichuan province randomly, 150 questionnaires were issued in different universities, of which 138 questionnaires were recovered, the recovery rate was $92 \%$, which 136 was valid questionnaires, the efficient rate was $98.6 \%$. Among the 138 students, there were 90 male students and 48 female students.

\section{B. Research tool}

1) School belonging scale

PSSM, the "school belonging scale (PSSM Chinese Edition)", the scale consists of 18 items, including a sense of belonging, identity, school attachment, and so on. In the items, if student fully agree with the item, the score is 6 , if student do not agree with it completely, the score is 1 , the total scores is the sum of every item score. The higher the total scores, the higher the school belonging. After inspection, the reliability of this scale was 0.835 .

\section{2) Learning burnout scale}

In the "learning burnout scale", there were five level scoring system, "certainly not" is 0 , "not" is 0.25 , "sometimes not "is 0.5 ," the most is " 0.75 ," must be " is 1 . If the total score is between 0 8 points, it shows the learning burnout is relatively small, if the total score is between $9 \sim 14$ points, if indicates the problems of learning burnout exist, if the total score is between15 28, it shows the problems of learning burnout are serious, more than 20 indicates the learning burnout is very serious, after inspection, the reliability of this scale was 0.921 . 
C. Research on the situation of school belonging of university students

This study survey the school belonging from the following types: the gender, type of subjects, origin, and grades.
Whether there are differences between the grade and other demographic variables, the results were shown in the Table 1.

TABLE I. THE SITUATION OF SCHOOL BELONGING OF UNIVERSITY STUDENTS

$\begin{array}{ccc} & & \text { SB (School Belonging) } \\ \text { Gender } & \text { M } & 66.50 \\ & \text { F } & 70.91 \\ \text { Type of Subjects } & \text { Arts } & 71.05 \\ & \text { Science } & 68.57 \\ \text { Origin } & \text { City } & 97.38 \\ & \text { Country } & 98.95 \\ & \text { Freshman } & 98.68 \\ \text { Grades } & \text { Sophomore } & 98.24 \\ & \text { Junior } & 98.60 \\ & \text { Senior } & 92.39\end{array}$

This scale is based on the 4 level scoring system, the higher the score, the higher the sense of school belonging. from the table 1, it can be seen that the overall level of school belonging overall is not high in gender, school belonging score of girls is higher than boys, but there is no significant difference; from the type of subjects, liberal arts students' score is higher than science students, there were significant differences; and the school belonging from Country students is higher than the students from city, but there is no significant difference; from the Grades, it can be seen that the higher the grade, the higher the school belonging.

\section{Analysis on learning burnout}

In order to explore the situation of learning burnout, the research also be analyzed from the gender, subject types, origin and Grades. The situation of learning burnout between grade and other demographic variables were shown in Table 2.

TABLE II. THE SITUATION OF LEARNING BURNOUT OF UNIVERSITY STUDENTS

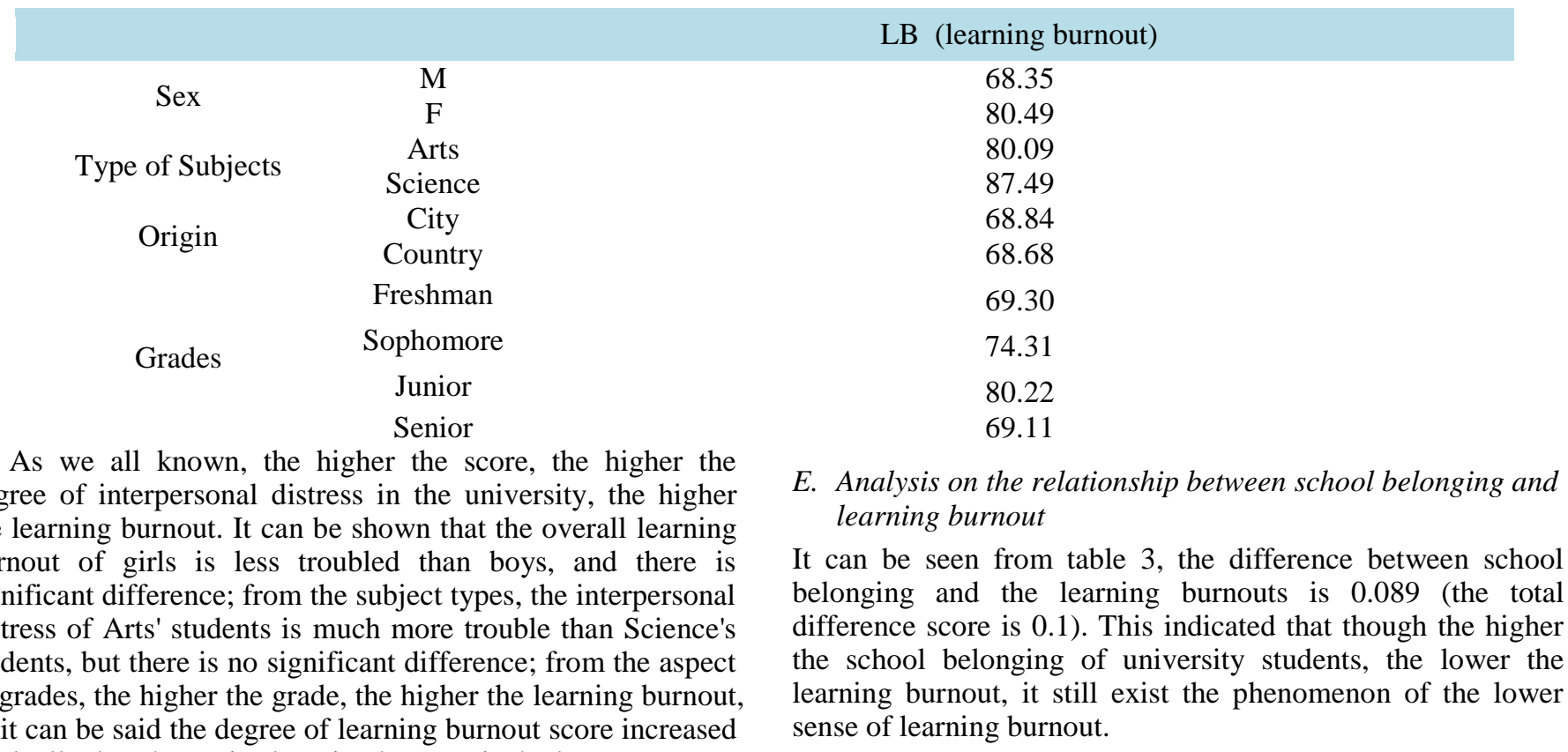




\section{learning burnouts}

\section{school belonging}

In order to further analyze the factors that influence the relationship between the school belonging and the interpersonal relationship, the school belonging factors were

\section{$0.089^{* * * *}$}

taken as predictor variables, learning burnout were taken as the dependent variable for linear regression analysis, the results are shown in Table 4.

TABLE IV. RELATIONSHIP BETWEEN THE SCHOOL BELONGING FACTORS AND LEARNING BURNOUT

$\begin{array}{ccc} & \text { R (Relationship) } & \text { LB (Learning Bunrout) } \\ \text { Belongs } & 0.603 & -0.112 \\ \text { Identity } & 0.738 & -0.298 \\ \text { School attachment } & 0.801 & -0.374\end{array}$

From the table 5, it can be seen that the three factors are becoming more and more important variety for the learning burnout, and the variable factor of belonging, identity, school attachment are $-0.112,-0.098$ and -0.374 respectively, it is also shown that the above results of the Table 4 is right, though there is a direct ratio between school belonging and learning burnout, the difference variate also still exist.

\section{DISCUSSION}

For university students. it means that they begin to start new life in a new environment, students want to gain acceptance, respect and support, and want to take part in the school activities, so the feeling of school belonging is becoming more and more important for them.

The total score of school belonging of girls was slightly higher than boys, but the difference was not significant, which was similar to that of Anderman. It probably because the girls have delicate feelings, when they become a member of a university, their feelings of the school will be more profound and delicate; however, the boys do not pay attention to the emotional details, so their sense of belonging is not outstanding.

The liberal arts students' score is higher than that of science students. This may be because the iberal arts students is more human, and they are easy to involve the emotions, feelings, so the school belonging and attachment experience are much more profound than science students; Therefore, liberal arts students have stronger sense of school belonging.

As for the place of origin, there is no significant difference between rural and urban students in their sense of school belonging. This may be because the gap between the rural and city is becoming more and more small, the background, economic situation also tends to be equal, and there has no obvious difference between urban and rural areas.

\section{ACKNOWLEDGMENT}

This research was financially supported by "Research on the Construction of Cultural Education and Cultural Education Modes from the Perspective of Marxist Human Being's Allround Development Theory" (Grant NO.18SB0281) .

\section{REFERENCES}

[1] Janis, W. Fostering School Connectedness. Research Facts and Findings.

[2] Bao Kebing, Xu Qinmie. Study on the Relationship between School belongs and Students' development. Psychological Exploring.,vol. 26, pp. 51-54,2006

[3] Anderman, E. M. School Effects on Psychological Outcomes during Adolescence. Journal of Educational Psychology, vol. 94, pp. 795,2002 